\title{
How to measure development in corpora? An association strength approach
}

\author{
Stoll, Sabine ; Gries, Stefan Th
}

\begin{abstract}
In this paper we propose a method for characterizing development in large longitudinal corpora. The method has the following three features: (i) it suggests how to represent development without assuming predefined stages; (ii) it includes caregiver speech/child-directed speech; (iii) it uses statistical association measures for investigating co-occurrence data. We exemplify the implementation of these proposals with data on the acquisition of the patterning of tense and grammatical aspect of four Russian children. The method, however, is suitable for a wide range of other acquisition questions as well.
\end{abstract}

DOI: https://doi.org/10.1017/S0305000909009337

Posted at the Zurich Open Repository and Archive, University of Zurich ZORA URL: https://doi.org/10.5167/uzh-86459

Journal Article

Published Version

Originally published at:

Stoll, Sabine; Gries, Stefan Th (2009). How to measure development in corpora? An association strength approach. Journal of Child Language, 36(5):1075-1090.

DOI: https://doi.org/10.1017/S0305000909009337 
7. Child Lang. 36 (2009), 1075-1090. (C) 2009 Cambridge University Press doi:I0.1017/So305000909009337 Printed in the United Kingdom

\title{
How to measure development in corpora? An association strength approach*
}

\author{
SABINE STOLL \\ Max Planck Institute for Evolutionary Anthropology, Leipzig
}

AND

STEFAN TH. GRIES

University of California, Santa Barbara

(Received 2 I February 2007. Revised 1о March 2008. First published online I6 February 2009)

\begin{abstract}
In this paper we propose a method for characterizing development in large longitudinal corpora. The method has the following three features: (i) it suggests how to represent development without assuming predefined stages; (ii) it includes caregiver speech/child-directed speech; (iii) it uses statistical association measures for investigating cooccurrence data. We exemplify the implementation of these proposals with data on the acquisition of the patterning of tense and grammatical aspect of four Russian children. The method, however, is suitable for a wide range of other acquisition questions as well.
\end{abstract}

\section{INTRODUCTION}

The study of language development in corpora involves changes over time in the frequencies of occurrence of some linguistic variable or, alternatively, changes of co-occurrence of two or more variables. The way development is characterized, however, varies from researcher to researcher, which renders comparisons across studies difficult. In this paper we propose a method to characterize development and exemplify this proposal on the basis of the

[*] This paper was mainly written during the second author's stays at the Max Planck Institute for Evolutionary Anthropology. We warmly thank Elena Lieven, Michael Tomasello and Bernard Comrie for providing such a stimulating and fascinating work environment. We thank Roland Meyer, who has done a wonderful job in developing a morphological tagger for Russian, and Tatjana Welikanowa and Madelaine Taoubi for help with coding. We are grateful to Balthasar Bickel, Elena Lieven and two anonymous reviewers for valuable comments. Address for correspondence: Sabine Stoll, Department of Linguistics, Max Planck Institute for Evolutionary Anthropology, Deutscher Platz 6, o4Io3 Leipzig, Germany. e-mail: stoll@eva.mpg.de 


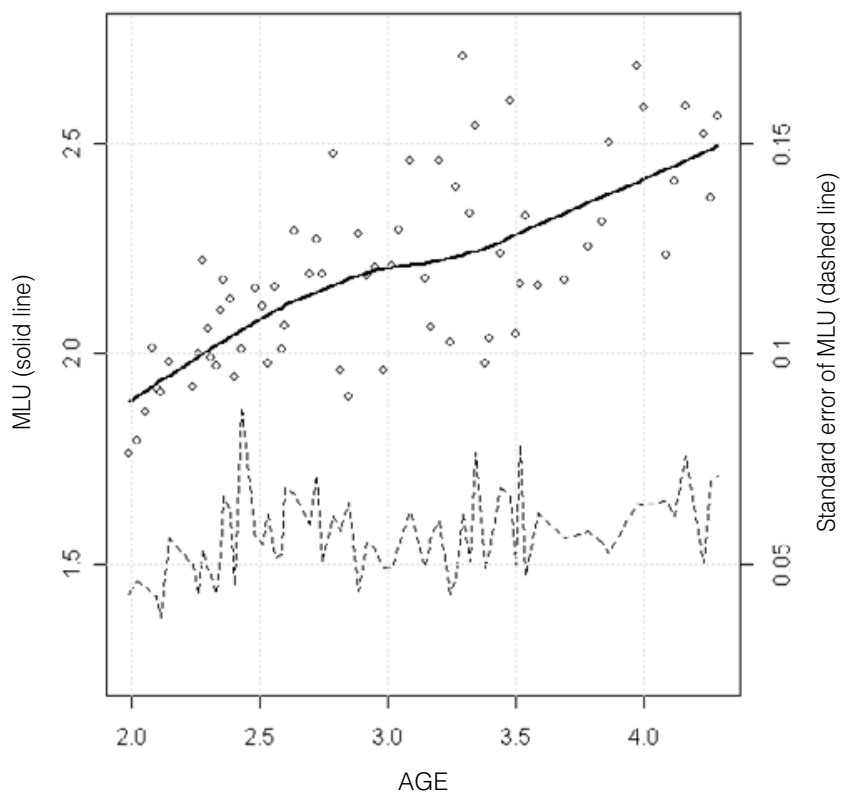

Fig. I. MLUs of Child 5 between I ; I I.28 and 4 ; 3. I 2.

development of tense/grammatical aspect correlations in a longitudinal corpus of Russian children.

Often in developmental research recordings are grouped into stages before analyzing the variable of interest. This is problematic for several reasons. First, any grouping of the data - i.e. the transformation of an otherwise rather continuous variable into a very small number of groups - results in the loss of information and preserves, at best, the ordinal information of the group (cf. Baayen, 2004: Section 2). Second, it is unclear on what basis to group the data. Age (as in the study on aspect by Li, Maher, Newark \& Hurley, 200 I) is often not a reliable predictor of morphosyntactic development, which is basically why Brown (1973), and after him many others, relied on mean length of utterance (MLU) as a more useful indicator of stages (cf. Bloom, Lifter \& Hafitz, I980; Shirai \& Andersen, I995, for studies on aspect). However, MLU values are notoriously variable and unstable. We show this in Figure $\mathrm{I}$, in which the solid line summarizes the dotted MLU values (in words) of 66 recordings (lasting approx. I hour each) of Child 5 from the Stoll corpus of Russian language acquisition (Stoll, unpublished data). The child's age is expressed in decimal format on the left $x$-axis (for example, $2 ; 6.0$ is expressed as $2 \cdot 5$ ). The lower dashed line plots the sizes of the standard errors of the MLU values against the right $y$-axis at a higher resolution. Given the 
large variability exhibited in the data, it is probably fair to assume that unless an extremely explicit procedure is used, different researchers are unlikely to recognize the same MLU-based stages (cf. Gries \& Stoll, to appear, for an algorithm solving this problem).

Finally, even if the classification based on MLU values were more reliable, it is not always obvious what is gained by such a classification (cf. Gries \& Stoll, to appear) because, if, for instance, we are interested in tense/ aspect marking, there is no obvious reason why the stages should be based on age, MLU or some other measure rather than on the phenomenon of interest, i.e. tense/aspect markings (as in Aksu-Koç, I998).

Another problem in the study of many phenomena and also in the study of tense/aspect is that we know very little about how the data of the children and the caregivers compare. For instance, there are several studies of aspect that analyze the data of the caregivers in addition to the data of the children, but they all group the data into different kinds of stages so that the resolution is very coarse-grained and little direct comparison is made. Stephany's (1985) study of tense/aspect in Greek child language was the first to compare the correlations found in child-directed speech to those found in child speech. Her study is among the most comprehensive and she compares the child-directed speech of the four mothers in her corpus to the output of the children, finding that the two are distributionally very similar. In the mothers' speech $96 \%$ of all past forms are perfective, compared to I $0 \%$ of the children's past forms. However, few other studies perform similarly comprehensive comparisons. Shirai \& Andersen (r995) investigate the data of three English children, but only compare the children and their caregivers at a single MLU stage, thus development cannot be traced. Aksu-Koç (r 998) includes child-directed speech for one of her children and only a small interval is covered (child's age: I ; 3.3-I ; I . IO). Li et al. (200 I) provide fine-grained results by looking at how Vendlerian classes (lexical aspect) and tense/aspect marking develop over time, but they still group the data into year-long stages and thus lose precision.

A final issue concerns the way developmental trends are assessed. Simple percentages (as in Shirai \& Andersen, I995) and linear correlations are probably the most widely used measures. However, linear correlations such as product-moment correlations or linear regression make assumptions that are not always met (for instance, bivariate normal distribution and normally distributed residuals with similar variances). Li (2002) uses both simple chi-square tests and multifactorial log-linear models to study the correlation between Aktionsart, aspect markers in Mandarin Chinese, and age. This method does justice to the multifactorial nature of the phenomenon but the age-based stages still give rise to the above-mentioned problems.

In the following, we make several methodological suggestions for studying development in language acquisition that address the shortcomings 
discussed above, focusing on quantitative analyses of distributional data from corpora:

(i) to avoid a loss of information due to grouping, we make use of all individual data points;

(ii) to better capture the covariation of the two variables, here tense and grammatical aspect, we use an association measure instead of cross-tabulation of pooled data (Cramer's $V$, cf. Bortz, Lienert \& Boehnke, I990: Section 8. I);

(iii) to better compare how development takes place, we compare association statistics for children and caregivers; and

(iv) to track developmental patterns in a noisy data set, we use smoothing and advanced regression techniques instead of simple linear regression models.

The proposed method is illustrated with a case study on the acquisition of Russian tense/aspect. However, it can be applied to a wide range of developmental questions that are based on the co-occurrence of two grammatical or lexical elements, such as the use of nouns vs. pronouns in different constructions to test for preferred argument structure, to give just one example.

\section{CASE STUDY: TENSE/ASPECT CORRELATIONS IN RUSSIAN}

Studies on a wide variety of languages have shown that in early acquisition there is a strong correlation between grammatical aspect (as a formal category, such as, for instance, perfective vs. imperfective) and tense, as well as between lexical aspect (Aktionsarten, such as for instance telics vs. duratives) and tense (for summaries see Li \& Shirai, 2000; Weist, 2002). The correlation between tense and grammatical aspect as observed in the literature can be characterized as follows: "verbs with past tense marking "for a bounded value" of grammatical aspect (e.g. perfective) are very likely to be telic whereas verbs with non-past marking for an unbounded value of grammatical aspect (e.g. imperfective or progressive) are likely to be non-telic' (cf. Shirai, Slobin \& Weist, I 998: 246). Results concerning the strength of the association and its development over time vary, which may be due to the different age ranges studied and the different methods used. In this note we suggest how the strength of associations can be measured by explicit mathematical procedures as exemplified in a large corpus of Russian child language.

\section{Aspect in Russian}

Concerning grammatical aspect, Russian distinguishes between perfective and imperfective. Every verb is either perfective or imperfective with a 1078 
number of bi-aspectual verbs (cf. Chertkova, I996, about the increasing number of bi-aspectual verbs in Russian). Perfective is the marked member of the opposition and can be defined as expressing the action 'as a total event summed up with reference to a single specific juncture' (Forsyth, I970: 8), e.g. On napisal pis'mo 'He wrote the/a letter' (i.e. the writing was completed). Thus perfective aspect in Russian activates a boundary of the event described and one of the possibilities is that the boundary corresponds with the concept of completion. Imperfective aspect is unmarked and may or may not refer to the boundaries of the action expressed by the verb, e.g. On pisal pis'mo 'He wrote a/the letter' or 'He was writing a/the letter'. Grammatical aspect systematically interacts with tense. Russian has three tenses : past, present and future. Imperfective aspect occurs in all three tenses, but perfective aspect has only a past tense form and a future tense (which has the same ending as the imperfective present tense). In interaction with aspect the tenses get their specific meaning, i.e. whether an action was or will be completed (in interaction with the perfective aspect) or simply was, is or will be ongoing (in interaction with the imperfective aspect).

Since our main concern here is methodological, we do not discuss tense/ aspect patterning in detail (for a proposal for qualitatively interpreting the development of tense/aspect through the tracking of the development of individual predicates, see Weist, Pawlak \& Carapella, 2004). We therefore concentrate on the association between tense and grammatical aspect (rather than between tense and lexical aspect) because grammatical aspect is morphologically coded and thus accessible in a Russian corpus (Stoll, unpubl. data). We also disregarded all imperatives and imperfective future forms since they are not relevant for the present study. Imperatives have aspect but no tense and imperfective future is an important tense in Russian but in this paper we concentrate on the question of whether the interrelation with present tense and imperfective and past tense and perfective also holds in Russian child language and child-directed speech.

\section{METHOD}

\section{Data}

Our case study is based on the caregiver/child interactions of four Russian children (two sibling pairs) taken from a longitudinal corpus of Russian language acquisition (cf. Stoll, unpubl. corpus). ${ }^{1}$ All four children are monolingual Russian children living in St. Petersburg, Russia. Child 3 and Child 5 are the target children of the longitudinal recordings. Child 4 is the older brother of Child 3 and Child 6 is the older brother of Child 5. The

[I] In the longitudinal study six children were studied. Child I and Child 2 of the longitudinal study are not part of the present study. 
TABLE I. Summary of the analyzed recordings

\begin{tabular}{|c|c|c|c|c|}
\hline Child & Age span & Recordings & Child utterances & Caregiver utterances \\
\hline Child 3 & I ; I I.28-4;3.I 2 & 80 & 6,796 & $3 \mathrm{I}, 687$ \\
\hline Child 4 & $3 ; 1.8-6 ; 7.12$ & II 7 & I9,652 & 50,6 I I \\
\hline Child 5 & $2 ; 3.17-5 ; 6.26$ & 66 & I I, 447 & 20,749 \\
\hline Child 6 & II $77.18-$ I 3 ; I I I I & 42 & 5,524 & I 2,697 \\
\hline
\end{tabular}

mothers were students and lived either in a communal apartment (Child 3 and 4 ) or in an extended family setting (Child 5 and 6); this means that sometimes several other caregivers were present during the recordings. The children were recorded weekly, mainly with video at their homes in free interaction with their caregivers. Child 3 and Child 4 were recorded together as were Child 5 and Child 6. Child 4 and Child 6 did not take part in all the recordings and to the same extent because they were not the target children of the longitudinal study but merely part of the natural environment of the target children. The earlier recordings of Child 3 were not part of this study since they did not contain any verbs. Child 4 was 3 ; I at the first recordings and his tense/aspect behavior was analyzed for the present study. Child 6, who was i I years old at the beginning of the study, served as a control child for the present study. The recordings consisted of undirected interactions and were made with a wide-angle lens without an experimenter present.

\section{Procedure}

The data were transcribed by a Russian native speaker, double-checked by the mother of the children, and morphologically tagged by an automated stochastic tagger (Meyer, 2003). The tagger is $92-94 \%$ correct overall; however, for verbs the rate is nearly 100\% because of the near absence of ambiguous forms. Nevertheless, the tags for each verb were checked manually by a linguist. The only mistakes found were a handful of names that were erroneously tagged as verbs, but no other mistakes occurred. Table I summarizes the number of utterances of the four children and their caregivers. 'Caregivers' here is a cover term for all adult native speakers providing input to the child during the recordings.

From each recording, we retrieved all verb forms produced by the child and his/her caregivers and extracted the code for the speaker and the annotations of tense and aspect for the verb forms. (All retrieval operations, as well as statistical computations and plots, were performed with $\mathrm{R}$ for Windows 2.4; cf. R Development Core Team, 2006). Crucially, and as mentioned above in (i), no grouping of the data into stages was performed. 
HOW TO MEASURE DEVELOPMENT IN CORPORA?

TABLE 2. Tense $\times$ aspect correlation of Child 3 at age $2 ; 7.28$

\begin{tabular}{lrrr}
\hline Child 3 & Non-past & Past & Totals \\
\hline Imperfective & 25 & 5 & 30 \\
Perfective & 5 & IO & I5 \\
Totals & 30 & I 5 & 45 \\
\hline
\end{tabular}

\section{MEASURE OF ASSOCIATION STRENGTH}

Since we are interested in the probabilistic association between tense and aspect in each individual recording (cf. suggestion (ii)), we use a probabilistic measure of association to quantify the association, namely Cramer's $V$, as our most central statistic. Cramer's $V$ is computed from a $\chi^{2}$-statistic for contingency tables, as shown in ( $\mathrm{I}$ ) where the expression ' $\min [$ no. of rows, no. of columns]' represents the smallest dimension of table.

(I) Cramer's $V / \varphi=\sqrt{\frac{\chi^{2}}{n \cdot(\min [\text { no of rows, no of columns }]-\mathrm{I})}}$

For 2 by 2 tables of the kind that we will report on in this paper, the denominator simplifies to $n$ and Cramer's $V$ is therefore equivalent to Pearson's contingency coefficient $p h i{ }^{2}$ Both range from o to $\mathrm{I}$. It is close to o when aspect and tense are not correlated, and the closer it is to I the stronger the correlation. Note that (I) also means that Cramer's $V$ is independent of the sample size, which allows us to compare the associations of tense and aspect in differently sized recordings.

We then cross-tabulated all present tense forms and all past tense forms of each recording for the child and, separately, for the caregivers so that $-\mathrm{cf}$. suggestion (iii) - pairwise comparisons are possible. For example, for the recording of Child 3 (at age $2 ; 7.28$ ) and her caregivers, the observed frequencies provided in Table 2 and Table 3 were obtained. The $\chi^{2}$-values for these tables are $\mathrm{II} \cdot 25$ and $3 \mathrm{I} \cdot 036$ respectively (at $d f=\mathrm{I}$, both of these are highly significant), and Cramer's $V$ for each table is 0.5 and 0.402 respectively. Analogous computations were performed for all recordings.

Finally, for each child and their respective caregivers, we generated a scatterplot of Cramer's $V$ values such that the recording time is on the $x$-axis and Cramer's $V$ is on the $y$-axis, applying statistical methods to characterize the observed developmental trends.

[2] This dependency of Cramer's $V$ entails that $V$ 's interpretation at least with regard to statistical significance is subject to the same constraints as all chi-square tests. Thus, one could not use the measure to test a $2 \times 3$ tense/aspect system having an empty cell. 
TABLE 3. Tense $\times$ aspect correlation of the caregivers of Child 3 at age $2 ; 7.28$

\begin{tabular}{lccc}
\hline Caregivers Child 3 & Non-past & Past & Totals \\
\hline Imperfective & I I 2 & I 4 & I 26 \\
Perfective & 35 & 3 I & 66 \\
Totals & I 47 & 45 & I 92 \\
\hline
\end{tabular}

\section{RESULTS}

\section{Child 3}

Child 3 is the youngest child in this study and was just starting to use verbs in the sessions chosen for this analysis ( 1 ; I r .28). Thus, given the findings in the literature, we expected to find the strongest developmental trend in this child. Figure 2 gives the results for Child 3 and also shows linear regression lines and their $95 \%$ confidence bands.

In both the data of the child and in the data of the adults we find large variation in the correlation of tense and grammatical aspect over time. However, the range of occurring values differs strongly in the child and the adults. The data of Child 3 exhibit considerable variation $(\max =\mathrm{I} ; \min =$ $0.0 \mathrm{I} 6$; mean $=0.452$; variation coefficient $=0.44){ }^{3}$ The data of the adults, however, exhibit less heterogeneity $\left(\max =0.559 ; \min =0 . \mathrm{I}_{3} ;\right.$ mean $=0.364$; variation coefficient $=0 \cdot 24)$. The Cramer's $V$ values for Child 3 exhibit a decreasing trend $\left(R^{2}=0 . \mathrm{I}_{5} ; F(\mathrm{I}, 78)=\mathrm{I}_{3} .74 ; p<0.00 \mathrm{I} ;\right.$ intercept $=0.8 \mathrm{I} 6$; slope $=-0$. I I 29), whereas the Cramer's $V$ values for her caregivers do not $\left(R^{2}=0.02 ; F(\mathrm{I}, 78)=\mathrm{I} \cdot 2 ; p=0.276 ;\right.$ intercept $=0.4 \mathrm{I} 5 ;$ slope $\left.=-0.0 \mathrm{I}_{59}\right)$. This is what we would expect. First, as Cramer's $V$ for the caregivers is approximately 0.4 , the caregivers exhibit the preferred correlation between tense and grammatical aspect observed in previous studies, but do not exhibit any development. Second, the child starts out with a conservative correlation between tense and grammatical aspect and this correlation weakens later in development.

However, problems with the linear regressions quickly become obvious. First, when the validity of the linear regression is tested, it turns out there are clear $U$-shaped relations between the residuals and the fitted values for both the child and her caregivers. Second, the regression lines leave a lot of variability unaccounted for. Third, the valid range of prediction for the linear regression is small: for the child, the regression equation predicts that Cramer's $V$ will be slightly smaller than $\circ$ at approximately age $7 ; 3$,

[3] The variation coefficient is a measure of dispersion that is better suited for comparing different dispersions across measures and samples than the standard deviation, as it is a function of the absolute amount of dispersion, rather than being normalized to one as in the standard deviation. It is computed by dividing the standard deviation of a distribution by its mean. 

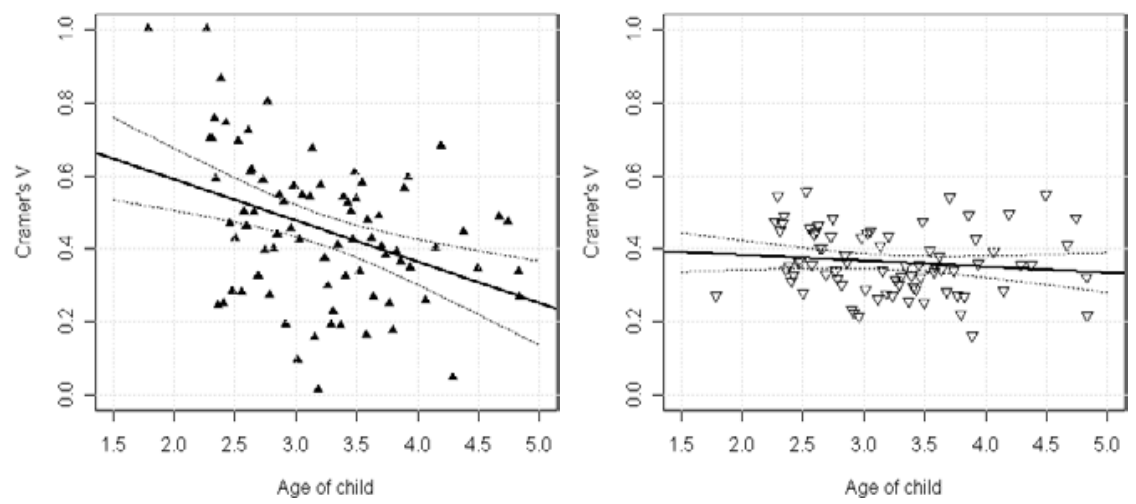

Fig. 2. The tense $\times$ grammatical aspect correlation of Child 3 (left) and her caregivers (right): linear regressions and confidence intervals.
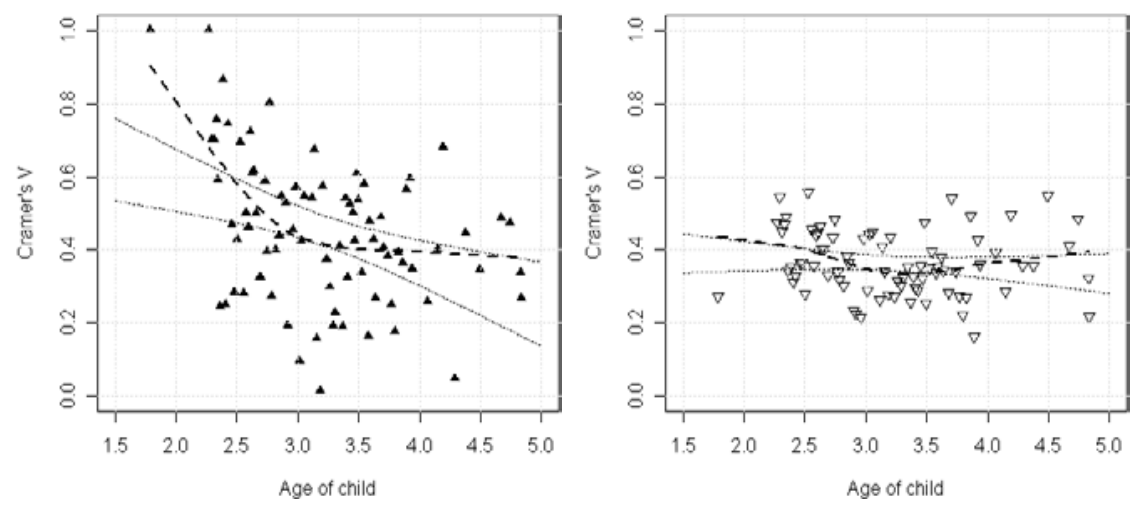

Fig. 3. The tense $\times$ grammatical aspect correlation of Child 3 (left) and her caregivers (right): confidence intervals of linear regression and locally weighted regression line.

which its mathematical properties render impossible. Thus, in order to better summarize the development of the Cramer's $V$ values over time, we replaced the linear regression line with a smoother resulting from a locally weighted linear regression (as implemented in R; cf. Cleveland, I979).

As shown in Figure 3, the linear regression line does not represent the kind of curvature obtained in the child's data very well, whereas the smoother picks out two markedly different developmental phases. The child moves from a very strong correlation of tense and grammatical aspect at the beginning to more flexible behavior with the strength of the correlation decreasing over time until approximately age $3 ; 0$. Around age $3 ; 0$, the curve flattens 

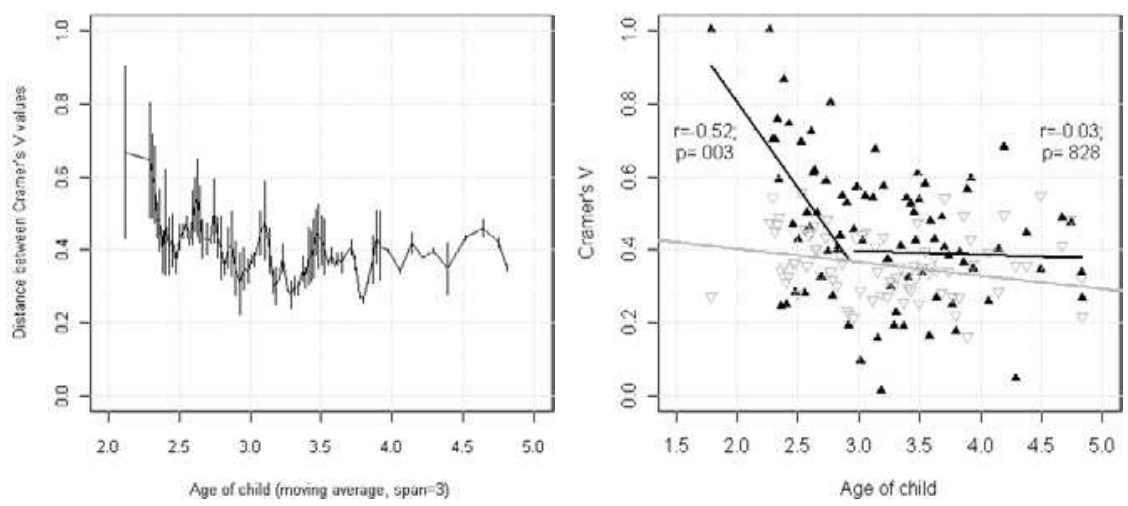

Fig. 4. The tense $\times$ grammatical aspect correlation of Child 3 (left) and her caregivers (right): differences between Cramer's $\mathrm{V}$ values and regression with breakpoints.

considerably and then strongly resembles the curve of the caregivers. While the child is more conservative in her marking than her caregivers for nearly all recordings, around $3 ; \circ$, her tense/aspect patterning approximates that of the adults very closely. By contrast, given the (expected) absence of development for the caregivers, their smoothing curve results in the same interpretation as the straight linear regression line does for Figure 2.

The overall developmental trend is also reflected clearly in the left panel of Figure 4, where we plot the differences between the Cramer's $V$ values of the child and her caregivers as vertical lines against the age of the child (using moving averages across three recordings). Going from left to right, the differences between the association strengths of Child 3 and her caregivers decrease (the vertical bars become shorter) as the child approximates the distributional patterns of the adult more and more closely (the bars tend to center around the caregiver mean of around $0 \cdot 4$ ).

Finally, let us note that there is a way in which an extension of regular linear regressions may be useful, namely regression with breakpoints (cf. Baayen, 2008: Section 6.4; Crawley, 2002: Chapter 22, for details about this approach). We iteratively split up the data at every individual recording into an early part and a late part and then computed linear regressions in which the dependent variable was the vector of Cramer's $V$ values of the child, and the independent variable was the interaction between the child's age and an indicator variable that marks each age as being part of the early or the late part. For each of these regressions, we stored the model deviance and then chose the model whose breakpoint was smallest and after which only increasing deviances were found. The two regressions following from this - one before the breakpoint, one after it - are shown in the right panel of Figure 4 . 

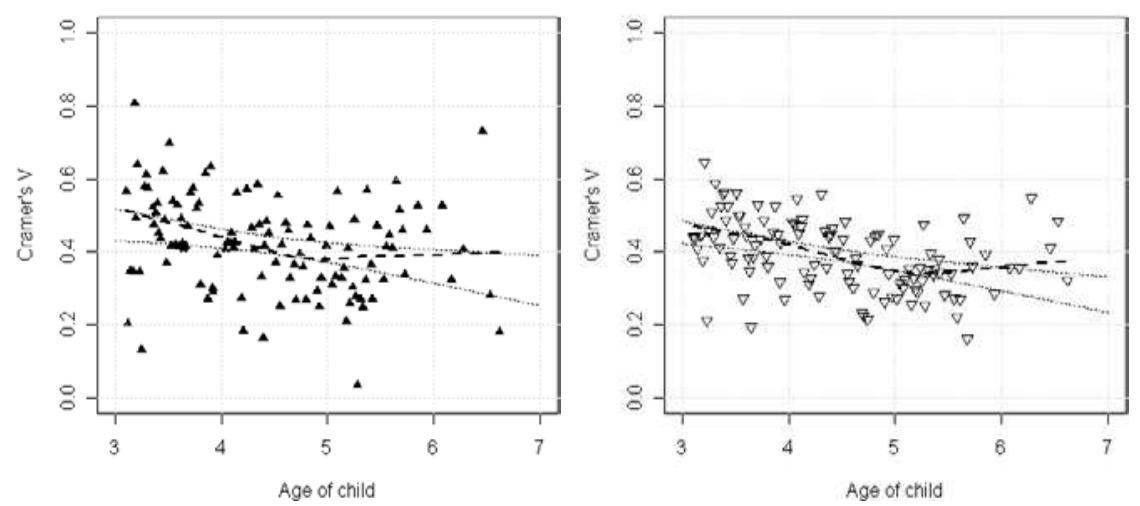

Fig. 5. The tense $\times$ grammatical aspect correlation of Child 4 (left) and his caregivers (right): confidence intervals of linear regression and locally weighted regression line.

Model comparison shows that the breakpoint at this location is highly warranted: if the amount of variance the linear model with the breakpoint explains $\left(R^{2}=0.266\right)$ is compared to that of the linear model without the breakpoint from above, it emerges that the regression with a breakpoint can explain significantly more variance $(F(\mathrm{I}, 77)=\mathrm{I}$ I.99I $; p<0.00 \mathrm{I})$. In addition, the result nearly perfectly replicates the results of the smoother: from shortly before 2;0 until approximately 3;0, there is a strong downward trend (note the correlation coefficient, which is much larger than the one obtained for all of the data). As of $3 ; 0$, on the other hand, there is no more development and the slopes of regression lines of the both the child and her caregivers do not differ significantly from o anymore. The lack of a significant difference between the slopes of the regression lines after age 3 ; 0 reflects the lack of development found for both child and caregivers. It does not, however, mean that the heights of the Cramer's $V$ values do not differ significantly, which could be tested, e.g. with a paired Wilcoxon test. Both the smoother and the regression with breakpoints analysis reveal a bifurcation of the developmental data that simple linear summary statistics and premature groupings of the data might well have missed.

\section{Child 4}

Child 4 's recordings begin at a later age $(3 ; \mathrm{r} .8)$, more specifically at an age at which Child 3 has already begun to approximate the caregivers' patterning, which is why we expect a less pronounced developmental trend. Consider Figure 5, where again the left and right panels show the data for the child and his caregivers respectively. 

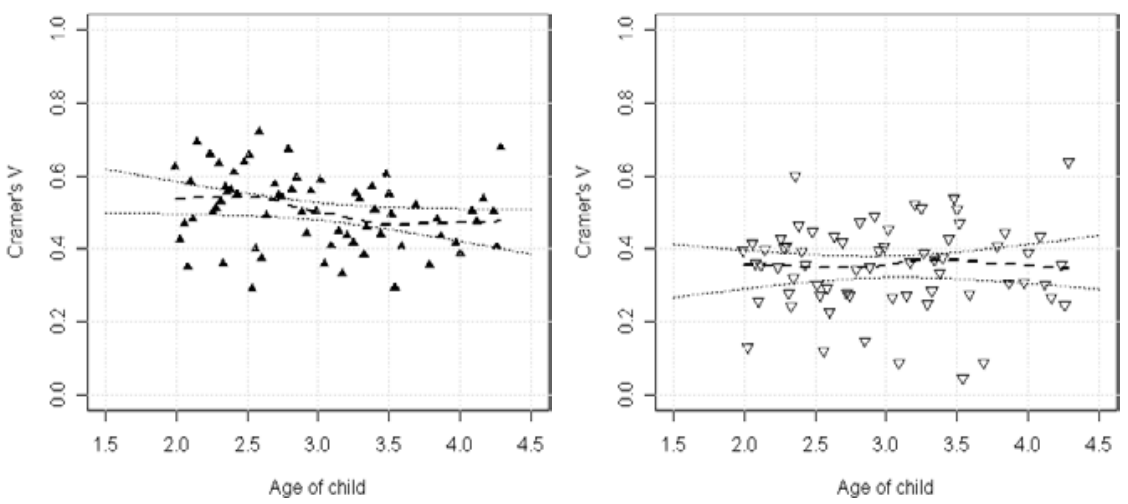

Fig. 6. The tense $\times$ grammatical aspect correlation of Child 5 (left) and his caregivers (right): confidence intervals of linear regression and locally weighted regression line.

On the one hand, we again find considerable variation. However, the range of occurring values differs strongly not only in the child and the adults but also between Child 4 and Child 3 . The data of Child 4 exhibit considerable variation $(\max =0.806 ; \min =0.037 ;$ mean $=0.4 \mathrm{I} 9 ;$ variation coefficient $=0.3 \mathrm{I}$ ), but much less so than Child 3 , as would be expected from the different age ranges. The data of the adults are again less heterogeneous $(\max =0.645 ; \min =0.163 ;$ mean $=0.392 ;$ variation coefficient $=0.24)$.

On the other hand, as to the developmental pattern, our expectation is again confirmed: (i) we find a much less strong developmental slope than for Child 3 ; but (ii) as of age 3 ; 0 , the slopes of the smoothing curves for both Child 3 and Child 4 are largely identical, descending only slightly; and (iii) both the overall mean and the overall slope for Child 4 are virtually identical to those of the caregivers.

\section{Child 5}

Child $5(2 ; 3.17)$ is slightly older than Child 3, but younger than Child 4, and a relatively early talker (especially in terms of lexical development). It is, thus, difficult to formulate precise predictions. Consider Figure 6.

These data differ from those for the first two children: Child 5 exhibits a relatively small degree of variation of the Cramer's $V$ values (max $=0.719$; $\min =0.29 \mathrm{I} ;$ mean $=0.388$; variation coefficient $=0.2)$. A further difference is that his caregivers' patterning is more heterogeneous $(\max =0.638 ; \min =$ 0.048 ; mean $=0.353$; variation coefficient $=0.33$ ). On the whole, the developmental pattern of Child 5 is less pronounced than that of Child 3 and more similar to that of Child 4. Still, across virtually all recordings the child is 

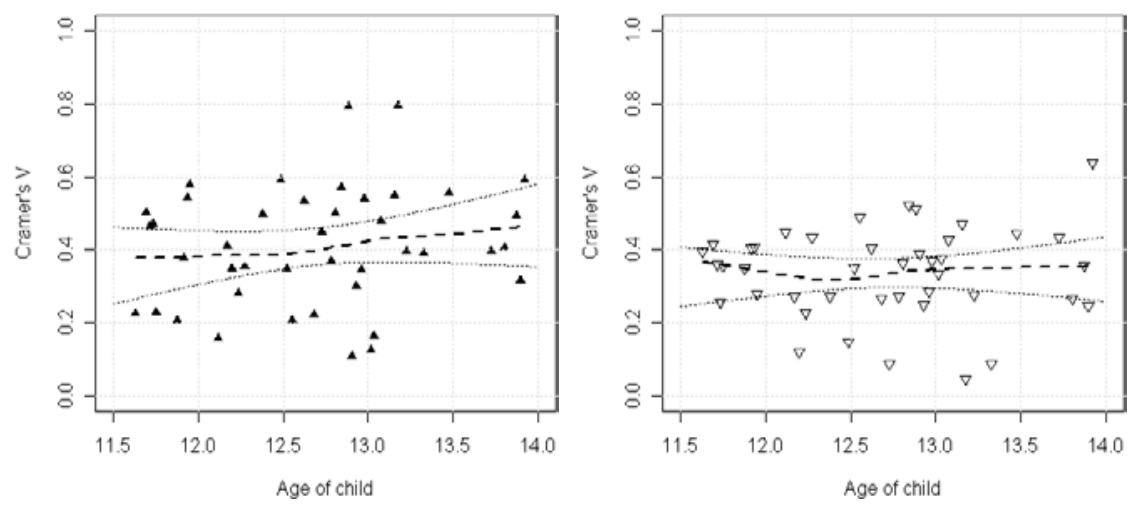

Fig. 7. The tense $\times$ grammatical aspect correlation of Child 6 (left) and his caregivers (right): confidence intervals of linear regression and locally weighted regression line.

again much more conservative than his caregivers, who, in turn, exhibit no developmental trend at all.

\section{Child 6}

As a control, we looked at the tense/aspect correlation of the eleven-year-old brother of Child 5 (I I;7.I8). If our method is on the one hand sensitive enough to identify developmental patterns, but on the other hand not oversensitive (such that one always obtains strong developmental curves and/or huge differences in terms of variation), then the data for Child 6 should resemble those of his caregivers very closely. This is exactly what we find, as is shown in Figure 7.

Both the data of the child and the data of the adults are rather similar in terms of their overall variation across the sessions (Child 6: $\max =0 \cdot 794$; $\min =0.109 ;$ mean $=0.409 ;$ variation coefficient $=0.4$; caregivers: $\max =$ $0.638 ; \min =0.048 ;$ mean $=0.337$; variation coefficient $=0.37$ ). Also, both curves do not exhibit any clear developmental pattern and are close to the results obtained for all previous adults just as would be expected for an eleven-year-old child.

\section{DISCUSSION}

The focus of this note was on the method we propose. However, there are also some findings on the development of tense/aspect in Russian. As in previous studies, we found the expected overall correlation between tense and grammatical aspect for both children and adults. Thus, for both adults and children there was a strong correlation between tense and aspect. 
The correlation in the children's earlier recordings, however, was much stronger than in the adults'. Our study confirms that the strong correlation children exhibit in early development weakens over time to a degree that is close or identical to that of the adults. However, this study is the first to show this with an association strength method that indicates the exact correlations between tense and aspect. Since we also avoid grouping, the methodology yields a continuous evaluation of the acquisition process and this type of analysis further enables us to determine, with a high degree of precision, the point at which the child's data resembles that of their caregivers.

Some of our results differ from those of previous studies. Li et al. (200 I : I30) state that "there seem to be "developmental" trends even in the parental input, in that the associations become weaker as the input age increases'. This does not correspond to our results, so we revisited their data. The correlation between tense and aspect in our data is compatible with the correlation between tense/aspect and Aktionsart in Li et al.'cs data. However, in our data, there is no developmental trend in the adult data: the overall average of the Cramer's $V$ values of all caregivers across all recordings is about 0.4 , with a small degree of variation and no systematic change. In Li et al.'s data there is a slight developmental trend: one cannot make such comparisons on the basis of provided chi-square values, but we computed effect sizes for their data and found Cramer's $V$ s of $0.355,0.27$ and 0.242 for their input stages.

We can only speculate where the difference between their results and ours comes from, but there are two likely explanations. First, Li et al. studied the correlation between tense (past, present progressive, third person singular $s$ ) and Aktionsart (process, state, etc.) and these data may pattern slightly differently from our data on tense (past vs. non-past) and grammatical aspect (imperfective vs. perfective) in Russian. Second, unlike Li et al., we did not lump the data of the caregivers into year-long stages. Not only is it unclear whether this division is motivated by something having to do with tense/aspect, this lumping may also hide significant differences among parts of the data that have been pooled. For example, Li et al. (200 I : I30) state that '[e]xamining each input stage separately, we found the same strong associations between lexical aspect and grammatical morphology as [in the pooled data]'. But this is actually not quite correct: the STRENGTH of the association obtained in their pooled data is much stronger, since Cramer's $V$ for the pooled data is 0.563 (rather than the above $0.355,0.27$ or 0.242 ). Thus, the sampling and successive grouping of the data has resulted in data that are quantitatively different and whose association strength is less homogeneous than assumed. We suggest that this underscores our reasoning against pooling and in favor of reporting association statistics for samples separately. 


\section{CONCLUSION}

We discussed four methodological proposals to help characterize development in large longitudinal corpora. First, these proposals avoid a need for stages and thus an overall loss of information, as well as the data loss and risks coming with grouping, rather continuous data into few groups. The approach is therefore fine-grained, but on the other hand we have shown it is not overly powerful since it is able to generate the expected null results for the control child. Second, the patterning of the child-directed speech is included and serves as a reference against which the children's data can be compared. Third, the proposed improvements over simple (linear) summary statistics - smoothing methods as well as regressions with breakpoints - show that sometimes only more refined methods can reveal the strongest and most interesting patterns, such as different developmental phases. Finally, instead of just reporting overall tables or percentages, we used a measure of association strength that allows to directly assess the issue at hand: the association between and co-occurrence of grammatical categories.

It is worth pointing out that the first three proposals can be applied regardless of whether the dependent variable is concerned with associated co-occurrence frequencies, as in the present example or any other kind of quantitative dependent variable (such as frequencies, or percentages). Finally, the proposed method is not restricted to the pairing of tense and aspect. In fact, any aspect of grammatical development that involves the co-occurrence of two lexical or grammatical elements is eligible for analysis with the proposed association strength approach.

\section{REFERENCES}

Aksu-Koç, A. (I998). The role of input vs. universal predispositions in the emergence of tense-aspect morphology: Evidence from Turkish. First Language r8, 255-80.

Baayen, R. H. (2004). Statistics in psycholinguistics: A critique of some current gold standards. Mental Lexicon Working Papers I, I-45.

Baayen, R. H. (2008). Analyzing linguistic data: A practical introduction to statistics. Cambridge: Cambridge University Press.

Bloom, L., Lifter, K. \& Hafitz, J. (I980). Semantics of verbs and the development of verb inflection in child language. Language 56, 386-4 I 2.

Bortz, J., Lienert, G. A. \& Boehnke, K. (I990). Verteilungsfreie Methoden in der Biostatistik. Berlin: Springer.

Brown, R. (I973). A first language: The early stages. Cambridge, MA: Harvard University Press.

Chertkova, M. I. (I996). Grammaticheskaia kategoriia vida v sovremennom russkom iazyke. Moscow: Izd-vo Moskovskogo universiteta [Moscow University Press].

Cleveland, W. S. (i 979). Robust locally weighted regression and smoothing scatterplots. Fournal of the American Statistical Association 74, 829-36.

Crawley, M. J. (2002). Statistical computing: An introduction to data analysis using S-Plus. Chichester: John Wiley and Sons.

Forsyth, J. (1970). A grammar of aspect: Usage and meaning of the Russian verb. Cambridge: Cambridge University Press. 
Gries, St. Th. \& Stoll, S. (to appear). Finding developmental groups in acquisition data: Variability-based neighbor clustering. Fournal of Quantitative Linguistics.

Li, P. (2002). Loglinear models for the analysis of language acquisition data. Cognitive Science 3, 27-4I.

Li, P., Maher, S., Newmark, E. \& Hurley, J. (200I). The role of parental input in the acquisition of tense-aspect morphology. Fournal of Cognitive Science 2, I I 9-43.

Li, P. \& Shirai, Y. (2000). The acquisition of lexical and grammatical aspect. Berlin/New York: Mouton de Gruyter.

Meyer, R. (2003). Halbautomatische morphosyntaktische Annotation russischer Texte. In R. Hammel \& L. Geist (eds), Linguistische Beiträge zur Slavistik aus Deutschland und Österreich. X. FungslavistInnen-Treffen, Berlin 200I, 92-105. München: Sagner.

$\mathrm{R}$ Development Core Team. (2006). $R$ : A language and environment for statistical computing. R Foundation for Statistical Computing: Vienna. www.R-project.org.

Shirai, Y. \& Andersen, R. W. (I995). The acquisition of tense-aspect morphology: A prototype account. Language 7I, 743-62.

Shirai, Y., Slobin, D. I. \& Weist, R. M. (1998). Introduction. In Y. Shirai, D. I. Slobin \& R. M. Weist (eds), The acquisition of tense-aspect morphology (Special Issue of First Language, vol. I8), 245-54. Buckinghamshire: Alpha Academic.

Stephany, U. (1985). Aspekt, Tempus und Modalität. Zur Entwicklung der Verbalgrammatik in der Neugriechischen Kindersprache. Tübingen: Narr.

Stoll, S. (unpubl. data). A corpus of Russian first language acquisition.

Weist, R. M. (2002). The first language acquisition of tense and aspect. In R. Salaberry \& Y. Shirai (eds), The L2 acquisition of tense-aspect morphology 2 $1-78$. Amsterdam, Philadelphia: John Benjamin.

Weist, R. M., Pawlak, A. \& Carapella, J. (2004). Syntactic-semantic interface in the acquisition of verb morphology, Fournal of Child Language 3I, 3 I-60. 